\title{
Superovulation treatments and embryo transfer in Angora goats
}

\author{
D. T. Armstrong*, A. P. Pfitzner, G. M. Warnes and R. F. Seamark
}

${ }^{*}$ M.R.C. Group in Reproductive Biology, and *Departments of Physiology and Obstetrics \& Gynaecology, The University of Western Ontario, London, Canda, and Department of Obstetrics \& Gynaecology, Queen Elizabeth Hospital, University of Adelaide, Adelaide, South Australia

\begin{abstract}
Summary. A high incidence of early luteal regression after PMSG superovulation was associated with low recovery of embryos from reproductive tracts of Angora goats flushed later than Day 5 after onset of oestrus. Embryos were successfully recovered (mean 7.9/female) by flushing on Days 2-5. Mean ovulation rate after an FSH regimen $(16 \cdot 1 \pm 0 \cdot 8)$ was significantly higher than that after a single injection of PMSG $(10 \cdot 8 \pm 1 \cdot 2)$. Fertilization rate and survival of embryos following transfer to naturally synchronized recipient feral goats did not differ between the two gonadotrophin regimens: the mean number of kids born to 47 donors treated with FSH $(7 \cdot 5 \pm 0.6)$ was significantly greater than that to 28 donors treated with PMSG $(4 \cdot 8 \pm 0.6)$. Irrespective of hormonal treatment, the numbers of embryos recovered and of kids born were correlated with ovulation rate $(r=0 \cdot 82, P<0.001$ for both). Embryo survival was influenced by ovulation rate in recipients, with $52 \%, 63 \%$ and $75 \%$ of transferred embryos being carried to term by recipients with 1,2 and $3 \mathrm{CL}$, respectively $(P<0.01)$. More embryos survived $(65 \%)$ when 2 embryos were transferred to each recipient than when $1(51 \%)$ or $3(48 \%)$ were transferred. In recipients receiving 2 embryos, survival was significantly improved by transfer of both embryos to the same oviduct $(70 \%)$ than when one was transferred to each oviduct $(62 \%)$. The percentage survival of embryos was optimal when oestrus of recipients was synchronized within \pm 1 day of oestrus in donors.
\end{abstract}

\section{Introduction}

Superovulation followed by recovery of embryos and transfer to appropriately synchronized recipients has proved an effective means of increasing the contribution of superior females to the gene pool of the population, a technique which has been applied especially effectively to dairy and beef cattle (reviewed by Seidel, 1981). This technique has also been applied to the genetic improvement of Angora goats (Moore, 1974; Moore \& Eppleston, 1979): progesterone was injected to control the cycle of donors, and a crude horse anterior pituitary gonadotrophin preparation was used to induce superovulation.

In a previous study a series of s.c. injections of a porcine pituitary FSH preparation produced a greater ovulation rate than did a single injection of PMSG, a lower degree of follicular hyperstimulation and less prolonged elevation of plasma oestradiol-17 $\beta$ concentrations during the preand post-ovulatory periods (Armstrong, Pfitzner, Warnes, Ralph \& Seamark, 1983). The present studies were undertaken to compare these two gonadotrophin regimens as methods of superovulation for use in an embryo transfer programme with Angora goats. Attempts were made to 
control as many sources of variation as possible, in order to determine optimal times and conditions of embryo collection and transfer for this species.

\section{Materials and Methods}

Donors of embryos were Angora goats that had been in oestrus at least once during the breeding season before being assigned to the superovulation treatment. Hormone treatments consisted of 750-1250 i.u. PMSG (Folligon: Intervet, Artarmon, Australia) administered as a single s.c. injection, or a porcine FSH preparation (FSH-P: Burns, Omaha, U.S.A.) administered twice daily over a 4-day period, total dose $18 \mathrm{mg}$. Gonadotrophin treatments were begun at various times during the oestrous cycle, from 8 to 18 days after the previous oestrus. During the superovulation treatment oestrus was induced by a single i.m. dose of $50 \mu \mathrm{g}$ cloprostenol, a PGF- $2 \alpha$ analogue (Estrumate: I.C.I., Macclesfield, U.K.) 2 days after the first injection of gonadotrophin, to trigger luteolysis.

Checks for oestrus were performed twice daily, with the aid of vasectomized males. Donors were hand mated to intact Angora males and 2 natural copulations were allowed at approximately 12-h intervals for as long as the females were in oestrus.

Recipients were feral or first cross (Angora $\times$ feral) goats that were exhibiting normal cycles and had been observed in oestrus at least once before use. The occurrence of oestrus was checked twice daily, and animals were considered to be in oestrus only if they stood while being mounted by a vasectomized teaser male. Most recipients were selected from a pool of normally cyclic females; only a few, towards the end of the transfer programme when the pool of cyclic recipients was becoming depleted, were synchronized with the donors artificially by means of cloprostenol administration.

Embryos were recovered surgically from donors sedated with thiopentone sodium and maintained in surgical anaesthesia with halothane. Before embryo recoveries, ovaries were examined by laparoscopy to determine degree of ovarian response to the gonadotrophin treatment. Females in which fewer than 4 ovulation points were observed were not used; they were given a luteolytic injection of cloprostenol and left at least one cycle before being treated again. Reproductive tracts of animals in which at least 4 ovulations were seen were exteriorized through a mid-ventral incision, and flushed with Dulbecco's phosphate-buffered saline (PBS), pH 7.2, containing $10 \%$ heat-inactivated $\left(55^{\circ} \mathrm{C}\right.$ for $30 \mathrm{~min}$ ) goat serum. A polyethylene tapered catheter, $1 \mathrm{~mm}$ o.d. at tip (tom-cat urethral catheter, Monoject, St Louis, U.S.A.) was inserted into the fimbriated end of the oviduct for a distance of approximately $2 \mathrm{~cm}$, and approximately $4 \mathrm{ml}$ PBS (warmed to $37^{\circ} \mathrm{C}$ ) were flushed through to the uterus. The flushings were recovered through a paediatric Foley catheter. This was inserted in the uterine horn just proximal to the bifurcation, and its bulb inflated with air. After flushing the oviduct contents into the uterus, $10-15 \mathrm{ml}$ of the same medium were flushed through the uterus by making a stab-wound through the uterine wall about 1 $\mathrm{cm}$ distal to the utero-tubal junction with a blunt needle. Thus a total volume of 14-20 ml PBS was flushed through each uterine horn. The flushings were collected in sterile plastic tubes with conical bottoms. These collection tubes were allowed to stand in a $37^{\circ} \mathrm{C}$ incubator for approximately 10 min, then aliquots from the bottom of each tube were transferred to sterile plastic Petri dishes for examination under a dissecting microscope. Embryos, which were readily recovered in this manner, were transferred immediately to fresh PBS containing $10 \%$ goat serum, and replaced in the $37^{\circ} \mathrm{C}$ incubator until transfer to recipients.

Transfers were performed to recipients under halothane anaesthesia. Exposure of the reproductive tract was achieved via mid-ventral incision. Number, positions and appearances of corpora lutea and large unovulated follicles were recorded. One, 2 or 3 embryos were transferred to each recipient. Except in the preliminary series, in which a comparison of transfers to oviducts and uteri was made, all embryos were transferred via a tom-cat catheter inserted into the fimbriated end 
of the oviducts, in the same manner as employed in the flushing procedure. Volumes of PBS were kept to a minimum of approximately 5-10 $\mu$ l per transfer.

Precautions were taken to minimize adhesions in donors and recipients. In particular, bleeding was kept to a minimum, and tracts were irrigated liberally with heparinized saline to prevent formation of blood clots.

After transfer, recipients were kept with vasectomized males equipped with marking crayons, to facilitate determination of return to oestrus. Donors were similarly kept under regular observation to determine time of return to oestrus. Donors were mated naturally at each oestrus after surgery until conception occurred.

Ova and embryos were evaluated microscopically at the time of collection. They were scored as 1-cell, 2- to 4-cell, 5- to 8-cell, or $>8$ cell. All ova which had cleaved were transferred, as were noncleaved ova recovered from donors flushed on Days 1 or 2 after the onset of oestrus. For 3 animals of the latter type, none of the ova had cleaved at the time of recovery, and all ova were transferred to a single intermediate recipient. The tract of the intermediate recipient was flushed 2-3 days later, and ova that had cleaved were transferred to a final recipient ( 1 or 2 embryos per recipient). Recovery and survival of embryos from this additional transfer did not appear to be different from that observed following a single transfer.

Data were assessed by analysis of variance, $\chi^{2}$ and linear regression analyses as appropriate.

\section{Results}

\section{Ovarian responses to superovulatory treatments}

Of a total of 80 gonadotrophin-treated females, 72 became oestrous and ovulated at least 4 ova each. Four females rejected on the basis of the laparoscopic examination were re-treated at least one cycle later, and 3 exhibited satisfactory superovulation. Of the 75 females whose reproductive tracts were flushed (28 PMSG-treated and 47 FSH-treated), 69 yielded viable embryos. Three females on each hormone regimen yielded only unfertilized ova. Ovulation rates and embryo recoveries were highly variable, ranging from 4 to 29 , and from 0 to 23 , respectively.

Duration of oestrus ranged from 1 to 3 days and was not significantly different in the FSHtreated (mean 1.5 days) and PMSG-treated (mean 2.0 days) females. The majority of FSH-treated females were first observed in oestrus within $24 \mathrm{~h}$ after the luteolytic injection of cloprostenol, whereas the interval from cloprostenol to onset of oestrus tended to be longer in PMSG-treated females (Text-fig. 1).
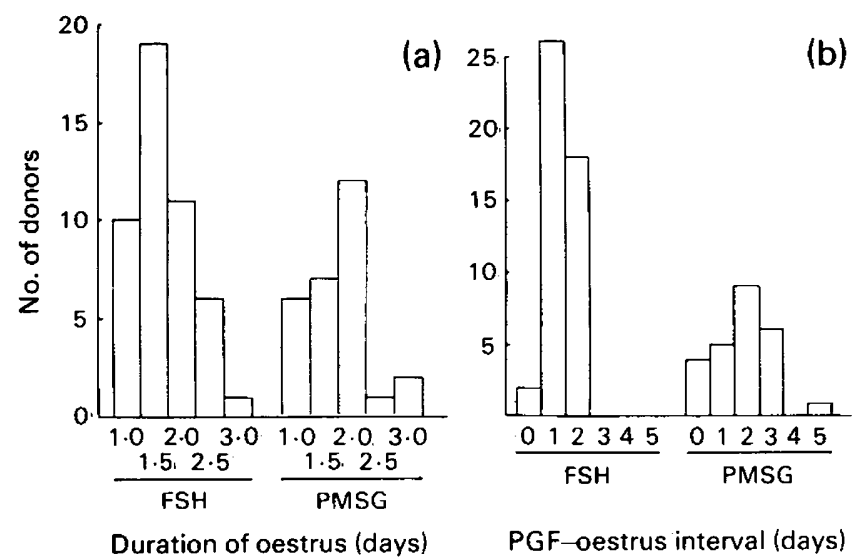

Text-fig. 1. Frequency distributions to show (a) the duration of oestrus and (b) the interval between cloprostenol administration and onset of oestrus in FSH- and PMSG-treated goats. Oestrus was checked twice daily, at approximately 12 -h intervals; animals exhibiting oestrus at two successive checks were classed as being in oestrus for 1 day. 
Effect of time of fushing on recovery and survival of embryos

In a preliminary trial with 23 PMSG-treated donors, the percentage of ovulated ova recovered as embryos progressively decreased as the interval from oestrus to flushing was increased (Table 1). The most dramatic decrease occurred when flushing was delayed beyond Day 5. Small avascular corpora lutea were noted in 5 of the 7 goats flushed at 6-8 days, and in 1 of 3 flushed on Day 5. Only one viable embryo was recovered from these 6 animals. In parallel with decreased recovery of embryos, the number of kids born after embryo transfer also decreased progressively with the greatest decrease for transfers after Day 5. No significant differences were seen in the percentage of transferred embryos which survived through pregnancy. There was therefore no evidence that recovered embryos were defective because of prolonged exposure to the donor's reproductive tract; the deficiency was in the ability to recover embryos as the interval from oestrus to flushing was increased. Subsequent donors were flushed before the 5th day after the onset of oestrus.

Table 1. Effect of time of embryo transfer on recovery and survival of embryos after induction of superovulation in goats with PMSG

\begin{tabular}{ccccc}
\hline $\begin{array}{c}\text { Time of transfer } \\
\text { (days after } \\
\text { onset of oestrus) }\end{array}$ & $\begin{array}{c}\text { No. of } \\
\text { females }\end{array}$ & Ovulations/donor & Embryos recovered & Kids born \\
\hline $2-3$ & 9 & $10 \cdot 3 \pm 1 \cdot 7$ & $8 \cdot 7 \pm 1 \cdot 4$ & $5 \cdot 1 \pm 0 \cdot 9$ \\
$4-5$ & 7 & $9 \cdot 4 \pm 2 \cdot 5$ & $7 \cdot 0 \pm 2 \cdot 3$ & $4 \cdot 3 \pm 1 \cdot 7$ \\
$6-8$ & 7 & $15 \cdot 5 \pm 2 \cdot 0$ & $2 \cdot 0 \pm 1 \cdot 4^{*}$ & $1 \cdot 1 \pm 1 \cdot 0^{*}$ \\
\hline
\end{tabular}

* Significantly lower than on Days $2-3$ and $4-5(P<0.01)$.

Values are mean \pm s.e.m.

Table 2. Embryo survival in goats as influenced by stage of development and site of transfer

\begin{tabular}{ccccc}
\hline $\begin{array}{c}\text { Stage of } \\
\text { development }\end{array}$ & $\begin{array}{c}\text { Site of } \\
\text { transfer }\end{array}$ & $\begin{array}{c}\text { Embryos } \\
\text { transferred }\end{array}$ & Kids born & $\begin{array}{c}\% \\
\text { survival }\end{array}$ \\
\hline 1- to 4-cell & Oviduct & 44 & 22 & $50 \cdot 0$ \\
5- to 8-cell & Oviduct & 42 & 29 & $69 \cdot 0$ \\
$>8$-cell & Oviduct & 34 & 23 & $67 \cdot 6$ \\
$>8$-cell & Uterus & 44 & 23 & $52 \cdot 3$ \\
\hline
\end{tabular}

Effect of stage of embryo development and site of transfer on embryo survival

Embryos recovered before they had divided beyond the 8-cell stage were transferred to the oviducts of recipients. Embryos which had developed beyond 8 cells were transferred to the oviducts or uterus. No significant differences were detected (Table 2). In particular, there was no evident advantage in transferring the more advanced embryos to the uterus, rather than to the oviduct.

\section{Embryo recovery and survival as influenced by gonadotrophin preparation}

The data in Table 3 for females flushed before Day 5 show that mean ovulation rate was significantly greater after superovulation induced with FSH than with PMSG. This increased ovulation rate was reflected in increased recovery of embryos, as well as in increased numbers of kids born. No significant differences due to treatment were noted in the percentage of ovulations recovered as embryos, or in percentage of transferred embryos carried to term. 
Table 3. Ovarian responses, embryo transfer and survival after induction of superovulation in goats with PMSG or FSH

\begin{tabular}{cccccc}
\hline & & & \multicolumn{2}{c}{$\begin{array}{c}\text { Ova or } \\
\text { embryos recovered }\end{array}$} & \\
\cline { 3 - 5 } Gonadotrophin & $\begin{array}{c}\text { No. of } \\
\text { females }\end{array}$ & Ovulations & Total & Fertilized & Kids born \\
\hline PMSG $\dagger$ & $28 \S$ & $10 \cdot 8 \pm 1 \cdot 2$ & $9 \cdot 0 \pm 1 \cdot 0$ & $7 \cdot 9 \pm 1 \cdot 0$ & $4 \cdot 8 \pm 0.6$ \\
FSH $\ddagger$ & 47 & $16 \cdot 1 \pm 0 \cdot 8^{*}$ & $13 \cdot 3 \pm 0 \cdot 7^{*}$ & $11 \cdot 9 \pm 0 \cdot 7^{*}$ & $7 \cdot 5 \pm \mathbf{0 . 6}$ \\
\hline
\end{tabular}

Values are mean \pm s.e.m.

$\dagger$ Folligon (Intervet) administered as a single s.c. injection, 750 or 1000 i.u.

† FSH-P (Burns) administered in 8 s.c. injections (a 4-mg injection followed by seven 2-mg injections at approximately 12 -h intervals).

$\S$ Includes PMSG-treated females flushed before Day 5 from Table 1.

* Significantly different from values with PMSG treatment, $P<0.001$.

Table 4. Embryo recovery and survival in goats as a function of ovulation rate

\begin{tabular}{|c|c|c|c|c|}
\hline \multirow{2}{*}{$\begin{array}{l}\text { Ovulations } \\
\text { per female }\end{array}$} & \multirow{2}{*}{$\begin{array}{l}\text { No. of } \\
\text { females }\end{array}$} & \multirow{2}{*}{$\begin{array}{c}\text { Embryos recovered } \\
\text { (\% of ovulations) }\end{array}$} & \multicolumn{2}{|c|}{ Kids born } \\
\hline & & & No. per female* & $\%$ of cleaved ova \\
\hline$\leqslant 10$ & 24 & $71.4 \pm 6.5$ & $3.9 \pm 0.8$ & $72.5 \pm 14.8$ \\
\hline $11-15$ & 22 & $68.6 \pm 6.7$ & $6.2 \pm 0.7$ & $69.5 \pm 4.6$ \\
\hline $16-20$ & 16 & $71 \cdot 5 \pm 7 \cdot 0$ & $8 \cdot 8 \pm 1 \cdot 1$ & $68 \cdot 8 \pm 6 \cdot 1$ \\
\hline $\begin{array}{l}\geqslant 20 \\
(21-29)\end{array}$ & 12 & $70.9 \pm 5.6$ & $10 \cdot 5 \pm 1 \cdot 2$ & $63.4 \pm 4.9$ \\
\hline
\end{tabular}

Values are mean \pm s.e.m.

* Significantly correlated with ovulation rate $(r=0.82, P<0.001)$.

\section{Effect of degree of ovarian stimulation on embryo recovery and survival}

There were significant $(P<0 \cdot 01)$ regressions of numbers of embryos recovered, and of kids born, on ovulation rate (Table 4). No significant differences were noted in percentages of ovulated ova recovered, or in survival to term, with increasing ovulation rate. Therefore, the number of kids born after transfer of embryos was directly proportional to ovulation rate

\section{Recipient factors influencing embryo survival}

Although every attempt was made to transfer embryos to recipients which were precisely synchronized with the donors, this was not always possible because of inadequate numbers of recipients. As a result, it was possible to evaluate the importance of exact synchronization by comparing embryo survival as a function of degree of asynchrony of donors and recipients (Table 5;

Table 5. Embryo survival in goats as influenced by degree of synchronization of donors and recipients

\begin{tabular}{lccc}
\hline $\begin{array}{c}\text { Stage of recipient } \\
\text { relative to donor }\end{array}$ & $\begin{array}{c}\text { Embryos } \\
\text { transferred }\end{array}$ & Kids born & $\%$ survival \\
\hline 1 day earlier & 16 & 8 & $50 \cdot 0$ \\
Same stage & 625 & 401 & $60 \cdot 0$ \\
1 day later & 121 & 68 & $57 \cdot 2$ \\
\hline
\end{tabular}


data from transfers in which degree of synchrony were not recorded are excluded). Survival did not differ significantly as long as degree of asynchrony did not exceed \pm 1 day.

Embryo survival as a function of recipients' ovulation rate is summarized in Table 6 for those recipients in which ovulation rate was recorded. Survival increased progressively and significantly $(P<0.01)$ as numbers of ovulations in recipients increased.

Embryo survival in relation to numbers of embryos transferred per recipient is presented in Table 7. Survival was significantly improved when 2 embryos were transferred. Over $80 \%$ of recipients of two embryos carried pregnancies to term, with approximately two-thirds of these giving birth to twins. Survival of embryos transferred as twins was significantly higher when both embryos were transferred to the same oviduct (unilateral transfer) than when one was transferred to each oviduct (bilateral transfer) (Table 8).

Approximately equal numbers of embryos were transferred to feral recipients, as to feral $\times$ Angora crosses (first generation). Mean percentage survival did not differ significantly between the two types of recipients.

Tables 4-8 in certain instances include data from donors in the preliminary trial (Table 1) where appropriate, and exclude data where recording deficiencies left some uncertainties. Therefore there are small differences in totals presented in these tables.

Table 6. Embryo survival in goats as influenced by ovulation rate of recipients

\begin{tabular}{ccccc}
\hline No. of CL & $\begin{array}{c}\text { No. of } \\
\text { recipients }\end{array}$ & $\begin{array}{c}\text { Embryos } \\
\text { transferred }\end{array}$ & Kids born & \% survival \\
\hline 1 & 135 & 225 & 123 & $51 \cdot 6^{*}$ \\
2 & 258 & 499 & 328 & $63 \cdot 1$ \\
3 or more & 23 & 44 & 33 & $75 \cdot 0$ \\
\hline
\end{tabular}
$0.01)$.

* Significantly less than for 2 or more corpora lutea $(P<$

Table 7. Effect of number of embryos transferred on embryo survival in goats

\begin{tabular}{ccccc}
\hline $\begin{array}{c}\text { No. of embryos } \\
\text { per recipient }\end{array}$ & $\begin{array}{c}\text { No. of } \\
\text { recipients }\end{array}$ & $\begin{array}{c}\text { Embryos } \\
\text { transferred }\end{array}$ & Kids born & \% survival \\
\hline 1 & 51 & 51 & 26 & $51 \cdot 6$ \\
2 & 329 & 658 & 429 & $65 \cdot 2^{*}$ \\
3 & 23 & 69 & 33 & $47 \cdot 8$ \\
\hline
\end{tabular}
0.01 ).

* Significantly greater than for 1 or 3 embryos per recipient $(P<$

Table 8. Survival of goat embryos transferred as twins to the same or opposite oviducts

\begin{tabular}{lcc}
\hline & \multicolumn{2}{c}{ Transfer } \\
\cline { 2 - 3 } & Unilateral & Bilateral \\
\hline Kids born/embryos transferred & $155 / 222$ & $259 / 420$ \\
Survival (\%) & $69.8^{*}$ & $61 \cdot 7$ \\
$\%$ of recipients kidding twins & $55 \cdot 8$ & $43 \cdot 8$ \\
$\%$ of recipients kidding singletons & $27 \cdot 9$ & $35 \cdot 7$ \\
$\%$ of recipients not kidding & $16 \cdot 2$ & $20 \cdot 5$ \\
\hline
\end{tabular}

${ }^{*} P<0.05$ 


\section{Discussion}

In common with most other species in which superovulation and embryo transfers have been carried out (reviewed by Betteridge, 1977), the goat exhibited a high degree of variability in ovulation rate and in numbers of embryos recovered after induction of superovulation. Although no attempt was made to titrate the gonadotrophin doses to the animals' body weights, no relationship was noted between body weight and number of ovulations in response to a given dose of hormone. Similarly, no correlation was observed between ovulation rate and stage of the oestrous cycle at which gonadotrophin treatment was begun. It seems likely that both genetic and nutritional factors contribute to the variability, but other unknown physiological variables cannot be ruled out.

In confirmation with results described previously with feral goats (Armstrong et al., 1983), a high incidence of premature corpus luteum regression was noted when laparotomies, to recover embryos, were carried out 6-8 days after the onset of oestrus. Very low rates of embryo recovery were achieved in donors exhibiting similar luteal failure. It seems likely that the failure to recover embryos under these conditions is a reflection of abnormalities in embryo transport, e.g. leading to expulsion via the cervix, as a result of endocrine abnormalities associated with the luteal failure. However, in preliminary studies aimed at preventing this loss of embryos, progestagen treatment administered by insertion of intravaginal progestagen-containing sponges on Day 3 did not improve rate of embryo recovery from females exhibiting luteal failure (Armstrong, Miller, Walton, Pfitzner \& Warnes, 1982). The reasons for the short luteal phases following superovulation are not known. Short luteal phases have been reported in naturally cyclic dairy and Angora goats, especially associated with "situations in which the endocrine requirements for a normal oestrous cycle are not fully met" (e.g. in kids, in the post-partum period, and at the end of the breeding season) (Corteel, 1977). The altered endocrine patterns associated with superovulation appear to be another such situation leading to premature luteal failure.

To circumvent the problem of low embryo recovery associated with luteal insufficiency, reproductive tracts were flushed between Days 2 and 4 after onset of oestrus, yielding high recovery rates. Survival of embryos transferred at these early stages was as good as that of those transferred at later stages. This is in contrast to the results reported by Moore \& Eppleston (1979), in which survival of embryos recovered 3.5 days after oestrus was only about half that of embryos transferred at later stages. The difference may be explained by the site at which the transfers were made. Moore \& Eppleston (1979) transferred the 3.5-day embryos which were mostly at 2- to 8-cell stages to the uterine horns, not the natural site for embryos at this stage of development (Amoroso, Griffiths \& Hamilton, 1942). In our study, embryos at this stage were transferred to the oviduct, the site from which they were recovered in the donors.

Although the success achieved by transferring embryos to the oviduct makes early embryo recovery feasible, if this is attempted too early, before first cleavage has occurred, it is not possible to distinguish fertilized from unfertilized ova at the magnifications available with an ordinary stereoscopic microscope. We have used two approaches to determine fertilization when singlecelled ova were recovered. The first was to transfer all ova to an intermediate recipient, from which they were recovered 2-3 days later, with only those which had cleaved being then transferred to final recipients. The second was to culture them in vitro for several hours to allow cleavage to occur. Survival rate of embryos obtained by both these procedures, upon transfer to recipients, did not appear to differ significantly from those of embryos collected at later stages of development and transferred immediately.

At the hormone doses used, ovulation rates were significantly higher in FSH-treated than in PMSG-treated donors. High rates of fertilization, approaching $90 \%$, were obtained with both treatment regimens, leading to significantly higher embryo recovery from FSH-treated animals. There was no evidence of lower fertilization rate in animals exhibiting higher ovulatory responses. Similarly, neither embryo recovery nor embryo survival upon transfer was clearly affected by higher ovulation rates. Thus, under the conditions, used, ovulation rate is the prime determinant of success rate (no. of kids born per donor). 
Considerable latitude was found in the degree of asynchrony between donor and recipient which could be tolerated. In confirmation of the findings of Moore \& Eppleston (1979) recipients could be out of phase with the donor by $24 \mathrm{~h}$ either way without adversely affecting embryo survival.

The highly significant relationship observed between ovulation rate in recipients and embryo survival raises the possibility that survival may be enhanced by higher circulating progesterone levels in recipients. If so, then it might be possible to improve survival by administration of exogenous progesterone to recipients, or by increasing their ovulation rate by administration of a small dose of gonadotrophin to recipients - a treatment which would be readily compatible with hormonal methods of synchronization of recipients with donors.

The improved embryo survival following twin transfers and the better survival of twin transfers when both embryos were placed in the same oviduct suggest that there is some type of synergism between embryos in influencing each other's survival upon transfer. Possible explanations for such co-operation include enhanced luteotrophic or anti-luteolytic actions resulting in improved luteal maintenance in recipients, or enhanced signals to the endometrium involved in the process of implantation (placental attachment). Whatever the explanation, the finding has important economic implications in enabling the embryo-carrying capacity of the recipient pool of goats to be doubled.

We thank Dr Alan Cotton and the Colchis Angora Stud, Nairne, South Australia, for providing the goats used in this research, which was supported by the M.R.C. of Canada and the Endocrine Fund, Queen Elizabeth Hospital, Adelaide. D.T.A. is a Career Investigator of the M.R.C. of Canada.

\section{References}

Amoroso, E.C., Griffiths, W.F.B. \& Hamilton, W.J. (1942) The early development of the goat. J. Anat. 76, $377-406$.

Armstrong, D.T., Miller, B.G., Walton, E.A., Pfitzner, A.P. \& Warnes, G.M. (1982) Endocrine response and factors which limit the response of follicles to PMSG and FSH. In Embryo Transfer in Cattle, Sheep and Goats, pp. 8-15. Eds J. Shelton, A. O. Trounson \& N. W. Moore. Austr. Soc. Reprod. Biol., Sydney.

Armstrong, D.T., Pfitzner, A.P., Warnes, G.M., Ralph, M.M. \& Seamark, R.F. (1983) Endocrine responses of goats to superovulation with PMSG and FSH. $J$. Reprod. Fert. 67, 395-401.

Betteridge, K.J. (1977) Superovulation. In Embryo Transfer in Farm Animals, pp. 1-9. Ed. K. J. Betteridge. Canada Dept of Agriculture, Monograph 16, Ottawa.
Corteel, J.M. (1977) Management of artificial insemination of dairy seasonal goats through oestrus synchronization and early pregnancy diagnosis. In Management of Reproduction in Sheep and Goats, pp. 24-25. University of Wisconsin, Madison.

Moore, N.W. (1974) Multiple ovulation and ovum transfer in the goat. Proc. Aust. Soc. Anim. Prod. 10, 246-249.

Moore, N.W. \& Eppleston, J. (1979) Embryo transfer in the Angora goat. Aust. J. agric. Sci. 30, 973-981.

Seidel, G.E., Jr (1981) Superovulation and embryo transfer in cattle. Science, N.Y, 211, 351-358. 